\title{
ПРИМЕНЕНИЕ РЕИНЖИНИРИНГА БИЗНЕС-ПРОЦЕССОВ К ЛОГИСТИЧЕСКИМ СИСТЕМАМ С УЧЕТОМ ИХ ОСОБЕННОСТЕЙ
}

\author{
(C) 2021 Сосунова Лильяна Алексеевна \\ доктор экономических наук, профессор \\ Самарский государственный экономический университет, Россия, Самара \\ E-mail:kafedra-kl@yzndex.ru \\ () 2021 Пермякова Алина Александровна \\ аспирант 3 курса \\ Самарский государственный экономический университет, Россия, Самара \\ E-mail: a_permyakova_a@mail.ru
}

В статье приведено определение бизнес-процесса и его составляющие, отражена необходимость не только описания деятельности компании системой взаимосвязанных бизнес-процессов, но и важность качественного преобразования процессов за счет реинжиниринга. Приведено определение реинжиниринга, являющегося объектом исследования и определение логистической системы, являющейся предметом исследования. Актуальность темы заключается в отступлении от общей для всех экономических систем подходности к процессу реинжиниринга и выделение особенностей применения к логистическим бизнес-процессам. В статье описываются особенности применения процесса реинжиниринга к логистическим системам с учетом их отличия от других экономических систем. Подробно рассмотрены логистические системы на трех уровнях: макрологистические системы, мезологистические системы и микрологистические системы. Также отдельно выделены особенности процесса реинжиниринга, связанные с реинжинирингом бизнес-процессов в различных функциональных областях логистики: закупочная логистика, организация складского хозяйства, логистика запасов, транспортная логистика, производственная логистика, распределительная логистика и информационная логистика.

Ключевые слова: Логистический бизнес-процесс, реинжиниринг, логистическая система.

Деятельность современных компаний состоит из множества бизнес-процессов, позволяющих достигать цели предприятия и развиваться в условиях конкуренции. Под бизнес-процессом понимается последовательность взаимосвязанных работ, направленных на достижение результата, выраженного в создании услуги или продукта в рамках предприятия.

Бизнес-процесс имеет вход (событие/мероприятие, инициирующее последовательную цепь действий) и выход (результат, позволяющий продолжить работу в рамках следующего, связанного бизнес-процесса, или являющийся итоговым продуктом/услугой для потребителя). Таким образом, вся деятельность экономической системы описана поэтапно взаимосвязанной системой бизнес-процессов, позволяющих создавать конечный продукт или услугу.

Вне зависимости от качества составления бизнес процесса на определенном этапе жизненного цикла компании, в ходе развития организации, а также вследствие изменения рыноч- ной среды бизнес-процессы должны улучшаться, чтобы компания не потеряла конкурентоспособность и развивалась.

Существует два подхода к улучшению бизнеспроцессов: инжиниринг и реинжиниринг. Под инжинирингом подразумеваются незначительные изменения, которые позволяют повышать эффективность всего бизнес-процесса, но незначительно. Реинжиниринг - это радикальный пересмотр всех этапов, переосмысление бизнеспроцесса, подразумевающий перепроектировку, которая в случае корректного подхода приводит к качественному скачку в итоговой эффективности создания продукта или услуги.

В данной статье рассматривается реинжиниринг бизнес-процессов в логистических системах. Логистическая система - это экономическая система взаимосвязанных элементов, позволяющая управлять материальными и сопутствующими (информационными, финансовыми) потоками.

Существует два подхода к классификации 
логистических систем - вертикальная и горизонтальная. При использовании вертикального подхода к классификации логистических систем можно выделить три уровня: макрологистическая система, мезологистическая система и микрологистическая система.

Макрологистическая система представляет экономическую систему, управляющую материальными потоками на макроуровне, то есть вне зависимости от территориального расположения входящих в нее структур. Такая система представляет интегрирование логистических функций структур разных стран и континентов. Особенности реинжиниринга бизнес-процессов в макрологистических системах заключаются:

- В необходимости учитывать законодательство стран-участниц такой системы. Одной из предпосылок реинжиниринга может стать изменение в законодательстве любой из стран.

- Кроме того, необходимо учитывать различные уровни экономического развития каждого участника логистической системы.

- Грамотном выстраивании информационных потоков с применением технологий, доступных каждому звену логистической системы.

- Макрологистические системы состоят из огромного количества бизнес-процессов, что обуславливает необходимость эффективного взаимодействия входящих в нее бизнес-процессов и выстраивание их таким образом, чтобы цель каждого бизнес-процесса не противоречила общей цели макрологистической системы.

Одним из ярких примеров причин проведения реинжиниринга макрологистических бизнес-процессов является внедрение обязательной маркировки товаров в России. Данное изменение в законодательстве стало причиной реинжиниринга многих логистических бизнеспроцессов, включая производство, складские операции и транспортировку товаров.

Мезологистическая система представляет собой систему, регулирующую материальные и сопутствующие потоки в рамках конгломератов, финансово-промышленных объединений или транснациональных корпораций. Такая система предусматривает наличие хозяйственнодоговорных связей участников, будь то холдинг или несколько разных компаний, объединившихся для достижения цели с наименьшими затратами при максимальной эффективности.

Совместное информационное поле, обязательное наличие договоров с жесткими услови- ями между участниками такой системы создают особенности проведения реинжиниринга в мезологистических системах:

1. Так как, в мезологистических системах преобладает логистика информационного характера необходимо учитывать, что количество информационных потоков больше, чем количество материальных. При отсутствии информации реинжиниринг может оказаться неэффективным, равно как и избыточный для конкретного звена информационный поток может снижать эффективность отдельно взятого бизнес-процесса, что приведет к громоздкости и снижению общей эффективности мезологистической системы.

2. При реинжиниринге мезологистической системы важно учитывать двойственную направленность - во внешнюю среду всей системы и внутреннюю. Если во внешней системе важна конкурентоспособность, то во внутренней - согласованность отдельных процессов, которая диктуется не внешней средой, а подчиняется общим целям. В данном случае важно то, что отдельные процессы могут быть менее эффективными, если это приводит к достижению стратегических целей.

3. Также важной особенностью при реинжиниринге мезологистических систем является необходимость учитывать диверсификацию деятельности субъекта. Диверсификация позволяет уменьшить общие риски, однако логистические процессы могут строиться разными способами для каждого вида продукции/услуг.

Предпосылками проведения реинжиниринга в мезологистических системах часто являются новые направления развития рынка в целом. Например, развитие рынка онлайн-торговли - причина внедрения новых логистических бизнес-процессов и как следствие - пересмотра многих уже существующих.

Микрологистические системы регулируют сферу деятельности одного предприятия либо конкретную отрасль деятельности крупного предприятия. Такие системы могут являться составными частями макрологистических систем или самостоятельными единицами, рассматривающими макрологистическую систему как внешнюю среду. Особенности реинжиниринга микрологистических систем в основном обусловлены тем, что в высокоинтегрированных макрологистических системах микрологистические системы функционируют эффективнее, 
поэтому при проведении реинжиниринга важно учитывать принципы работы макрологистической системы и стремиться к интеграции с ней.

При проведении реинжиниринга микрологистическиой системы также важно учитывать следующие особенности:

1. Взаимосвязи в такой системе построены на базе внутрипроизводственных отношений и в основном осуществляется безтоварное взаимодействие.

2. Необходим параллельный реинжиниринг двух уровней логистической микросистемы - верхнего уровня с ориентацией на внешние связи и нижний уровень, направленный на оптимизацию внутренних процессов.

3. При реинжиниринге микрологистических систем важно учитывать рационализацию горизонтальных связей для устранения излишней интеграции.

4. Важная задача реинжиниринга микрологистических бизнес-процессов - сокращение степени управленческого воздействия, если это целесообразно.

5. Необходимо учитывать единую инфраструктуру микрологистической системы.

Одной из распространенных причин реинжиниринга микрологистических систем является недостаточный уровень использования информационных технологий или использование устаревших технологий, что приводит к низкому уровню адаптивности всей системы по отношению к внешней среде и потере конкурентоспособности фирмы.

Помимо вертикальной классификации логистических систем выделяется горизонтальная, то есть функциональная классификация. В рамках функциональной классификации можно выделить логистические системы в области закупок, организации складского хозяйства, логистику запасов, транспортную логистику, производственную логистику, распределительную и информационную.

Задачей логистической системы в области закупок является организация закупок, а целью - минимизация затрат на закупку. Особенности реинжиниринга логистических бизнеспроцессов в области закупок:

1. Необходимо учитывать внешние связи с поставщиками;

2. Уделять внимание информационным системам контрагентов (поставщиков);

3. Ориентироваться на сбыт и текущие за- пасы предприятия;

4. Важно учитывать предпосылки реинжиниринга из-за затратности процесса. Если причина в оптимизации процесса, каковы отрицательные последствия для других логистических процессов. А если причина внешняя (изменение условий поставщика), возможно целесообразнее сменить поставщика, чем перепроектировать бизнес-процесс.

Особенности реинжиниринга логистической системы организации складского хозяйства сводятся к тесной взаимосвязи с другими функциональными областями логистики:

1. Минимизация затрат на хранение может быть достигнута в ущерб процессам транспортной логистики и за счет этого стать нецелесообразной.

2. При принятии решение об реинжиниринге складских процессов необходимо учитывать все возможные варианты: реинжиниринг процессов на собственном складе (например, за счет внедрения автоматизированных систем) может оказаться выгодным по отношению к текущему процессу, но не целесообразным в сравнении с вариантом использования арендованного склада.

Целью транспортной логистики является минимизация затрат на транспортировку материального потока, что обуславливает следующие особенности реинжиниринга:

1. Обеспечение единства с процессом организации складского хозяйства.

2. Согласованность между задачами транспортной логистики (например, способ транспортировки может не согласовываться с видами используемого транспорта)

3. Необходимость развивать гибкость транспортных бизнес-процессов для увеличения гибкости и степени адаптируемости всей компании к внештатным ситуациям (например, бизнес-процессы, исключающие возможность использования наемного транспорта могут отрицательно сказаться на эффективности всей логистической системы).

Особенность реинжиниринга бизнеспроцессов производственной логистики обусловлена тем, что предпосылками могут являться внешние факторы: маркетинговые исследования, изменения в законодательстве, например, введение маркировки, аналоги продукции на рынке и тд.

Логистические бизнес-процессы в области 
распределительной логистики направлены на минимизацию затрат на распределение продукции.

Реинжиниринг данных процессов должен предусматривать постоянно увеличивающееся разнообразие каналов распределения, а также методов распределения продукции.

При реинжиниринге процессов информационной логистики необходимо учитывать необходимость глубокой интеграции с бизнеспроцессами других функциональных областей для минимизации затрат на управление материальными потоками. В информационной логистике целью реинжиниринга редко является снижение затрат, чаще всего затраты увеличиваются, основная же цель - оптимизация остальных процессов за счет качественного управления информационными потоками.

В итоге можно выделить основные особен- ности реинжиниринга логистических бизнеспроцессов:

В разрезе функциональных областей логистики при проведении реинжиниринга любого бизнес-процесса необходимо учитывать особенность функциональной области логистики, ее задачи и взаимосвязь со смежными функциональными областям.

К сожалению, основным недостатком при проведении реинжиниринга является отсутствие учета влияния изменений конкретного бизнес-процесса на другие процессы компании.

Также при проведении реинжиниринга логистического бизнес-процесса необходимо учитывать, на каком уровне логистической системы проводится реинжиниринг. В зависимости от уровня логистической системы учитывать ее особенности для достижения максимальной эффективности процедуры реинжиниринга.

\section{Библиографический список}

1. Авторы теории реинжиниринга Майкл Хаммер и Джеймс Чампи - «Реинжиниринг корпорации: манифест революции в бизнесе» (1993 год)

2. Вирина К.В. Зарубежный опыт логистических бизнес-процессов в логистике // В сборнике: Молодежный научный форум. сборник статей по материалам CXV студенческой международной научно-практической конференции. Москва, 2021. С. 76-79.

3. Гришин И.С., Шихлерова Э. М. Реинжиниринговый подход для управления изменениями бизнес-процессов // Тенденции развития науки и образования. 2021. № 69-3. С. 34-39.

4. Елиферов В.Г. Бизнес-процессы. // Регламентация и управление 2004.

5. Палатай В.В. Реинжиниринг бизнес-процессов на предприятии // Современные научные исследования и инновации. 2021. № 1 (117). С. 21.

6. Пинаев Д. К. Моделирование бизнес-процессов: доступно о сложном [Текст]: справ. пособие / Д. К. Пинаев.М.: РГАС, 2017.- 247 с.

7. Попов Э., Шапот М. Реинжиниринг бизнес-процессов и информационные технологии. 2019 г.

8. Рубцова М.А. Совершенствование логистических процессов в системе менеджмента качества. Логистика по принципу FIFO на предприятии // Сборник трудов по материалам III Международного конкурса научноисследовательских работ. Уфа, 2021

9. Совин Г.А. Реинжиниринг бизнес - процессов // Управление компанией, № 6, 2008.

10. Хасанов Б.И. Алгоритм совершенствования бизнес-процессов в логистической системе малого предприятия. // Международный журнал гуманитарных и естественных наук. 2021. № 5-2 (56). С. 285-288.

11. Хлопенова Е.А. Реинжиниринг, понятие и концепция. // В сборнике: МОЛОДОЙ ИССЛЕДОВАТЕЛЬ: ВЫЗОВЫ И ПЕРСПЕКТИВЫ. Сборник статей по материалам CXCVIII международной научно-практической конференции. Москва, 2021. С. 188-193. 